\title{
Hyperhomocysteinemia: Relation to Cardiovascular Disease and Venous Thromboembolism
}

\author{
Nadja Plazar and Mihaela Jurdana \\ University of Primorska, College of Health Care Izola, \\ Slovenia
}

\section{Introduction}

Homocysteine is a sulphur-containing amino acid, which structurally is closely related to the essential amino acids methionine and cysteine. The cellular methylation cycle performs the metabolism of methionine and since homocysteine is an intermediate within this cycle, the body in this way is provided with all organic homocysteine. The term homocysteine is used to define the combined pool of homocysteine, homocystine, and mixed disulfide compounds (Fig. 1) even involving homocysteine thiolactone a cyclic form which is often found in the plasma of patients with hyperhomocisteinemia.<smiles>NC(CCSSCCC(N)C(=O)O)C(=O)O</smiles>

homocystine

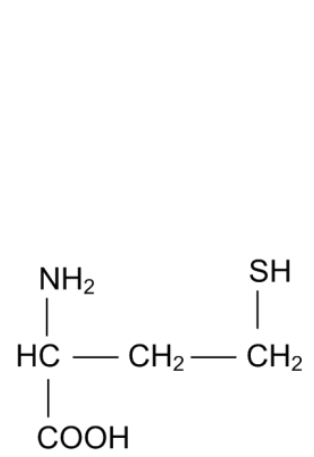

homocysteine<smiles>NC(CCSSCC(N)C(=O)O)C(=O)O</smiles>

cysteine- homocysteine

Fig. 1. Structural formulae of homocysteine

Homocysteine was first isolated by Butz and du Vigneaud in 1932. However, the relation of homocysteine to human disease was first suggested in 1962, in the classical paper of Carson and Neil, reporting an elevated homocysteine level in the urine of mentally retarded children. Nowadays, it has long been known that homocystinuria-also known as severe hyperhomocysteinemia, a genetic disorder in which blood levels of homocysteine are about 20 -fold higher than the normal concentration -is associated with greatly increased risk for 
premature vascular disease, occlusive cardiovascular disease in early life and childhood, leading to incidental strokes or heart attacks in teenagers. It is caused by inherited metabolic defects of the homocysteine metabolism, and is therefore positively correlated with a very high risk of venous thromboembolism (VTE), (Mudd et al., 1970).

These observations raised the question whether moderately elevated plasma homocysteine concentrations, often called moderate hyperhomocisteinemia, may also cause irritation of the blood vessels and are a risk factor for cardiovascular disesase (CVD) in general (McCully, 1960). McCully proposed that elevated homocysteine can cause atherosclerotic vascular disease (McCully, 1960). Early support for this concept came from a study published in 1976 by Wilcken and Wilcken, who reported that, following an oral dose of methionine, serum homocysteine levels tended to be higher in patients with premature coronary disease than in healthy controls (Wilcken \& Wilcken, 1976).

Mild or moderate hyperhomocysteinemia which occurs in the health population with a frequency of 5 to $7 \%$ is often caused by the interaction of environmental factors with mild genetic abnormalities of homocysteine metabolism.

Venous thrombosis was clearly described in patients with mild/moderate homocysteinuria and since then, several case-control and prospective studies showed the association with increased risk of VTE, (Mudd et al., 1985). Besides, also a large number of retrospective studies show that mildly elevated homocysteine levels (mild/moderate hyperhomocysteinemia caused by the interaction of envirovmental factors with mild genetic abnormalities of homocysteine metabolism) are associated with VTE. Only recently, an elevated homocysteine level has also been established as a risk factor for venous thrombosis (Moll, 2004). Moreover, in patients with venous thrombosis elevated homocysteine levels have attracted considerable interest because homocysteine is an easy to monitor thrombophilic marker, and thus can indicate the time and need for measures, to potentially reverse the venous thrombosis (Cattaneo, 2006).

Because of the already high prevalence of (hyper/moderate/mild) homocysteinemia in the healthly population and people with disease, this review focusses the attention on (1) the relevance of the metabolic pathway of homocysteine, (2) the importance of dietary intake of folate, vitamines B6 and B12 and (3) the recommendations to modify life style factors in order to prevent, in general, a further homocysteinemia-induced increase of the VTE and cardiovascular disease complications.

\section{Homocysteine metabolism}

\subsection{Plasma homocysteine}

As mentioned in the introduction homocysteine is a sulfur-containing intermediate in the normal metabolism of the essential amino acid methionine, occuring in almost all body cells and in general 5 to $10 \%$ of the daily synthesized homocysteine $(1.2 \mathrm{mmol} /$ day $)$ is transferred into the blood through hepatocytes (Weisberg et al., 2003). Besides, proliferating cells secrete more homocysteine compared to non-proliferating cells. Although plasma concentrations of homocysteine vary widely, on the other hand the intracellular concentrations are preserved within a narrow range (Moat et al., 2004). In the plasma, about circa $90 \%$ homocysteine is 
protein-bound, while circa $10 \%$ is present as the cysteine mixed disulphide and less than $1 \%$ is present in the free reduced form. The total plasma level includes the summed amount of all the homocysteine forms in the circulation (Hankey \& Eikelboom, 1999).

Normal and abnormal homocysteine levels are set by individual laboratories. Typically, considered normal is less than $13 \mu \mathrm{mol} / \mathrm{L}$, between 13 and $60 \mu \mathrm{mol} / \mathrm{L}$ is considered moderately elevated, and higher than 60 to $100 \mu \mathrm{mol} / \mathrm{L}$ is severely elevated (Moll, 2004). The total plasma homocysteine concentrations during hyperhomocysteinemia are between 12 and $30 \mu \mathrm{mol} / \mathrm{L}$, with gender differences being present. Higher values are measured in men, and apparently the presence of estrogen in women determines the plasma concentration after the menopause the blood levels of homocysteine of woman approximate those in men (Ridker et al., 1999), Table1.

\begin{tabular}{|l|l|l|l|l|l|}
\hline Sex & Age & Lower limit & Upper limit & Unit & Moderatelly elevated \\
\hline Female & $12-19$ years & 3.3 & 7.2 & $\mu \mathrm{mol} / \mathrm{L}$ & $13-60 \mu \mathrm{mol} / \mathrm{L}$ \\
\cline { 2 - 5 } & $>60$ years & 5 & 12 & $\mu \mathrm{mol} / \mathrm{L}$ & \\
\hline \multirow{2}{*}{ Male } & $12-19$ years & 4.3 & 9.9 & $\mu \mathrm{mol} / \mathrm{L}$ & $>11.4 \mu \mathrm{mol} / \mathrm{L}$ \\
\cline { 2 - 5 } & $>60$ years & 6 & 15.3 & $\mu \mathrm{mol} / \mathrm{L}$ & \\
\hline
\end{tabular}

Table 1. Blood reference ranges for homocysteine

The homocysteine levels are measured through a routine blood test, where blood samples are collected in EDTA or citrate anticoagulant tubes and should be centrifuged and the plasma separated immediately. Ideally, the homocysteine is measured in overnight fasting subjects, since high-protein meals will influence the results. Another test, the methionineload test measures the homocysteine levels before and after the intake of $100 \mathrm{mg} / \mathrm{kg}$ of methionine and can be used to diagnose abnormal homocysteine metabolism in people with a high risk for cardiovascular disesase, but who have normal homocysteine concentration during fasting. This test can be used to make decisions about therapy.

Homocysteine exists in plasma in a free and a bound form. The determination measures the total homocysteine level is the sum of all forms. The commercial methods of determination include the transformation of all forms of homocysteine, by means or reduction, into total homocysteine, which than is quantified by different methods: gas chromatography, mass spectrometry, high pressure liquid chromatography and the most frequently commercial methods as florescence polarization immunoassay, chemiluminescence immunoassay, or enzyme-linked immunoassay, used on different analyzers.

Results obtained with different methods are often not very com-parable each other because of considerable inter-method and inter-laboratory variability. Reported approaches for the measurement of plasma tHcys include: ion-exchange chromatography, immunoassays (fluorescence polarization immunoassay, FPIA, or chemiluminescence immunoassay, ICL,or enzyme-linked immunoassay, EIA), HPLC (with photometric, fluorescence or electrochemical detection),capillary electrophoresis with photometricor laser fluorescence detec- tion), GC-MS, and LC-ESI-MS/MS. Many of them have significant disadvantages, including derivatization protocols, are expensive and time-consuming. Compared with the above mentioned, LC-ESI-MS/MS seems to be the most suitable method because of its inherent accuracy, high sensitivity, specificity and high through put for $t$ Hcys analysis. 


\subsection{Role of B vitamins and enzymes}

B vitamins function as coenzymes in the synthesis of purines and thymidylate during normal DNA synthesis. Diminished levels of these vitamins may result in misincorporation of uracil into DNA, leading to chromosome breaks and disruption of DNA repair and both, folate and vitamin B12 levels are involved in DNA methylation. Deficient folate and vitamin B12 levels can reduce the availability of Sadenosylmethionine, the universal methyl donor, for DNA methylation and may thereby influence gene expression (Blount et al., 1997).

Some people have elevated homocysteine levels due to an unbalanced diet with suboptimal intake of B vitamins (B6, B12 and folate), which act as coenzymes in the metabolism of homocysteine (de Bree et al., 1997, Stanger et al., 2003). Several studies have found that high blood levels of B vitamins influence the integrity and function of DNA, and, correlate with a low concentration of homocysteine, while folate depletion has been found to change DNA methylation and DNA synthesis in both animal and human studies.

B vitamines are very important in the transformation of homocysteine in methionine and are cofactors to three important enzymes directly involved in the homocysteine metabolism: (1) methionine synthase (MS), (2) methylenetetrahydrofolatereductase (MTHFR) and (3) cystathione $\beta$-synthase (CBS).

Therefore, deficiencies of folate and vitamin B12 and reduced activity of the involved metabolic enzymes will inhibit the breakdown of homocysteine, leading to an accumulation of the intracellular homocysteine, followed by rapid excretion to the circulation and eventually increased plasma levels (Silaste et al., 2001).

Via the trans-sulfuration pathway homocysteine is converted into cystathionine to form cysteine by cystathionine-B-synthase, with vitamin B6 as a co-factor. Another pathway of homocysteine metabolism is the re-methylation pathway, which is connected with the folate metabolic pathway (Fig. 2). It involves the transfer of a methyl group from 5-methyltetrahydrofolate to homocysteine to form methionine, and eventually Sadenosylmethionine. The methyl transfer from 5-methyl tetrahydrofolate to homocysteine is catalyzed by methionine-synthase, and requires vitamin B12 as a cofactor. Important to notice is that S-adenosylmethionine is the universal methyl donor for methylation reactions. The resulting tetrahydrofolate transfers into the 5,10-methyltetrahydrofolate with the enzyme 5,10-methyltetrahydrofolate reductase (MTHFR) and then into the 5methyltetrahydrofolate 5-MTHF, (Fodinger et al., 2000). The cellular availability of 5-MTHF may be of great importance in regulating cellular effects of homocysteine related to cell growth.

The methyl group of 5-MTHF is transported to vitamin B12 linked to the enzyme homocysteine-methyl-transferase to yield methylcobalamin-enzyme. This complex adds the methyl group to homocysteine to form methionine (Pietrzik \& Brönstrup, 1998).

Therefore, deficiencies of folate and vitamin B12 and reduced activity of the involved metabolic enzymes will inhibit the breakdown of homocysteine, which will lead to an increase of the intracellular homocysteine concentration (Silaste et al., 2001). 


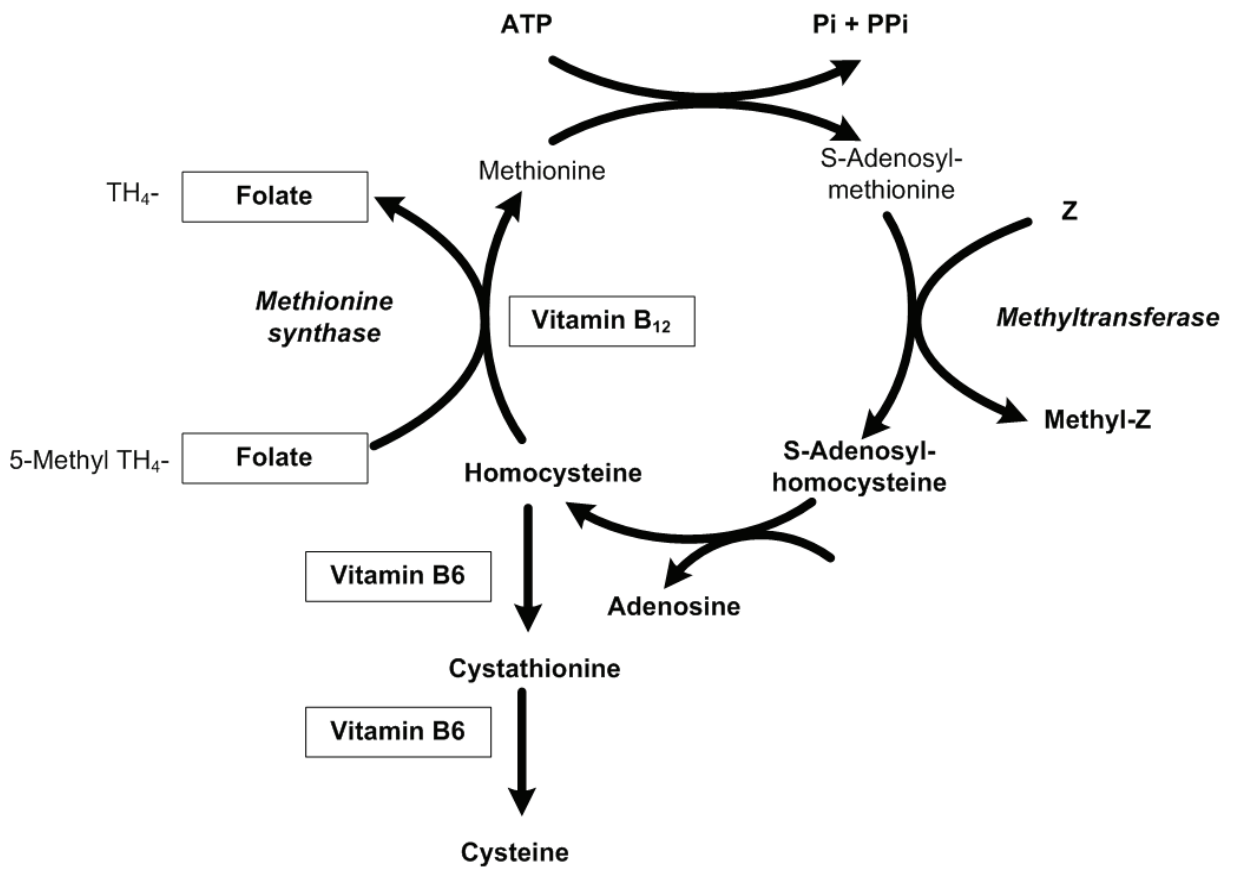

Fig. 2. Homocysteine metabolism

S-adenosylhomocysteine is formed during S-adenosylmethionine-dependent methylation reactions, and the hydrolysis of S-adenosylhomocysteine results in homocysteine. Homocysteine may be remethylated to form methionine by a folate-dependent reaction that is catalyzed by methionine synthase, a vitamin B12-dependent enzyme. Alternately, homocysteine may be metabolized to cysteine in reactions catalyzed by two vitamin B6dependent enzymes.

\section{Causes of hyperhomocysteinemia}

\subsection{Genetic deffects}

Elevation in plasma homocysteine are typically caused either by genetic defects in the enzymes involved in homocysteine metabolism or by nutritional deficiencies in vitamin cofactors. Homocysteinuria and severe hyperhomocystenemia are caused by rare inborn errors of metabolism resulting in marked elevations of plasma and urine homocysteine concentrations.

Most studies refer to changes in the cystathionine $\beta$-synthase gene or in the GCT gene ( $\gamma$ cystathionase), both coding the trans-sulfuration pathway (references). Further, mutations do occur in the genes coding for the enzymes involved. Cystathionine $\beta$-synthase (CBS) deficiency is the most common genetic cause of severe hyperhomocysteinemia. As first shown in a study by Carey and colleagues as early as 1968, the homozygous form of this disease - congenital homocystinuria - can be associated with hyperhomocysteinemia, and 
in these homozygotes there is a frequent development of atherothrombotic complications during young adulthood, which often are fatal. Mudd and colleagues estimated that approximately 50 percent of untreated homocystinuria patients will have a thromboembolic event before the age of 30 and that the disease-related mortality is approximately 20 percent (Mudd et al., 1970).

Other abnormalities of the remethylation cycle that are associated with hyperhomocysteinemia include genetic methionine synthase deficiency and genetic disorders of vitamin $B_{12}$ metabolism both impairing methionine synthase activity.

Genetic mutations in MTHFR are the most commonly known inherited risk factor for elevated homocysteine levels. To have any detrimental effect, mutations must be present in both copies of a person's MTHFR genes (Varga et al., 2005). (1) A point mutation in the coding region for the 5,10-MTHFR binding site (C677T), leading to the substitution of an alanine to a valine effectively increases homocysteine levels increase and decreases methionine levels or (2) A1298C another common point mutation of the MTHFR gene, both affect the enzyme activity catalyzing the vitamin $B_{12}$-dependent remethylation of homocysteine to methionine. C677T homozygotes carry the double TT (thermolabile) allele of the enzyme MTHFR gene of which the enzyme activity is reduced to $35 \%$ of the normal (Schriver et al., 1995), and having an average homocysteine level of $19.7 \mu \mathrm{M}$. In CT heterocygotes this is $10.3 \mu \mathrm{M}$, while for CC unaffected this is $10.0 \mu \mathrm{M}$. Further, data show that people with C677T TT have $21 \%$ increased risk of ischemic heart disease; in those with CT the risk is increased by only 6\% (Dinesh $-\mathrm{K}, 2004$ ).

Aproximally $10 \%$ to $20 \%$ of Caucasians carry the TT allele, whereas the remaining $80 \%$ $90 \%$ carry either the CT or CC alleles. Black subjects have a very low frequency of carring the TT allele. The C677T mutation does have different regional incidences in Europe where the German and Italian populations show different incidences of $24.5 \%$ and $43.8 \%$ respectively.

\subsection{Other disease states}

Hyperhomocysteinemia occurrs in a wide range of unrelated diseases as depicted in Table 1.

Over the past 15 years, there has been an explosion in the number of scientific articles describing an association between homocysteine and vascular disease. Hyperhomocysteinemia has been linked to an increased risk of cardiac events; sudden death; stroke; coronary- carotid- cerebral- and peripheral-arterial diseases. It is also implicated in transplant coronary artery disease and essential hypertension (Dinesh, 2004). In general, retrospective analyses show that for every $4 \mu \mathrm{M}$ rise in homocysteine levels, the relative risk for cardio vascular disease increases by 1.3 to 1.4 (Nygard et al. 1997a). Data obtained from (COMAC-European concerted Action Project (Graham et al., 1997), which studied patients with vascular disease and control subjects, confirmed that homocysteine levels more than $12 \mu \mathrm{M}$ increased the risk for all types of atherotrombotic vascular disease. So, after a thorough review of the available literature, hyperhomocysteinemia should be considered an independent risk factor for cardiovascular disease. 


\begin{tabular}{ll}
\hline Aging & Heart conditions \\
\hline Alzheimers disease & Mental retardation \\
\hline Anaemias & Migraines \\
\hline Angina & Miscarriages \\
Arthritis & Osteoporosis \\
\hline Artheriosclerosis & Parkinson's disease \\
Auto-immune diseases & Polycystic ovary disease \\
Birth defects & Pregnancy complications \\
Cancers & Psoriasis \\
Cholesterol - high & Rheumatoid arthritis \\
Chronic fatigue & Schizophrenia \\
Coeliac disease & Strokes \\
Chrohn's disease & Thyroid disorders \\
Depression & Ulcerative colitis \\
Diabetes & Epilepsy \\
\hline
\end{tabular}

Table 2. Common diseases associated with high homocysteine levels (Hultberg et al., 1993; Pettersson et al., 1998; Bolander-Gouaille, 2001; Hultberg, 1993).

\subsection{Lifestyle factors}

From a public health viewpoint, it is important to identify modifiable factors that influence the plasma homocysteine concentrations. The next lifestyle factors may have an effect on plasma homocysteine concentration (Bolander-Gouaille, 2001):

\subsubsection{Smoking}

Smoking is associated with vascular disease and other complications related to homocysteine (Bolander-Gouaille, 2001). The number of cigarettes smoked a day was one of the strongest determinants of homocysteine levels (Nygard et al., 1995). In women, the increase of plasma homocysteine levels was about $1 \%$ per each cigarette smoked, and in men about $0.5 \%$. The mechanisms by which smoking increases the homocysteine levels may be manifold, however there is some experimental evidence that nicotine directly affects the methylation reactions. Besides, in smokers catabolism of folate has been suggested(Godin \& Crooks, 1986).

\subsubsection{High alcohol intake}

High alcohol consumption is often associated with gastrointestinal disturbances, which may result in decrease absorption of vitamins (the most important is folic acid), thus contributing to elevated homocysteine levels. Alcohol has also been reported to inhibit methionine synthase (MS), to decrease hepatic uptake and increase excretion, mainly via urine (Barak et al., 1993). The decreased concentration of serum folic acid may occur in $80 \%$ of alcohol abusers and this can lead to serious clinical consequences. 


\subsubsection{Coffee consumption}

Coffee consumption has been associated with several risk factors for coronary heart disease, including plasma total homocysteine and reduced B vitamin concentrations (Ulvike et al., 2008). Coffee drinking is associated with smoking and low intake of fruit and vegetables. Tea consumption, in contrast, was associated with lower homocysteine levels (Nygard et al., 1997b).

\subsubsection{Inadequate nutrition}

B vitamins have been suggested to play a critical role to maintain low homocysteine levels (Silaste et al., 2001). A diet poor in fresh fruit and vegetables or strict vegeterians may develop nutritional vitamin B12 deficiency (Miller et al., 1991). This is particulary serious in pregnancy, as the mother may not be able to supply the fetus with sufficient vitamin B12. Also modern food processing may destroy essential vitamins and it has recently been shown that microwave heating may destroy as much as $30 \%$ of the vitamin B12 content in food (Watanabe et al., 1998). Prolonged heating may also destroy folate and vitamin B6. Besides, healthly subjects eating fish more than 3 times a week had lower homocysteine levels than those eating fish less than one a month.

\subsubsection{Physical activity}

Physical activity plays an important role in our life, since it is the cheapest way of strengthening our health and reduces the risk of developing cardiovascular diseases. It has been confirmed that physical activity decreases the concentrations of total plasma homocysteine and thus the probability of developing a cardiovascular disease in healthy and already sick people. In the study called Bed rest "The influence of simulated weightlessness upon the human organism" performed in 2006, 2007 and 2008 at the Valdoltra Orthopaedic Hospital, Slovenia, in which young male participants (age 24-30 years) rested in horizontal position for 35 days, a statistically increased homocysteine concentration was documented (Plazar et al., 2008). The diet composition and the energy intake were daily supervised and monitored by a dietician. Volunteers were non-smokers, non-alcoholics, without history of cardiovascular and neuromuscular disorders. Several studies indicate physical activity as an independent lifestyle factor connected with lower homocysteine concentration. Besides, exercise is associated with a reduction in plasma fibrinogen concentrations, and with increasing activity levels of exercise a reduction in homocysteine was observed. So, this prolonged bed rest study confirms that increased levels of homocysteine in blood, negatively influences the cardiovascular system. Although, the precise mechanism is not well understood, similar consequences can result from prolonged physical inactivity in everyday life.

\subsubsection{Age related factors}

Many studies have shown that hyperhomocysteinemia increases with age (Pennypacker et al., 1992). This is connected with inadequate nutrition, the changes in gastrointestinal function, B vitamins deficiency, enzyme defects, a higher occurance of the C677T mutation and numerous age-related physiological factors. 


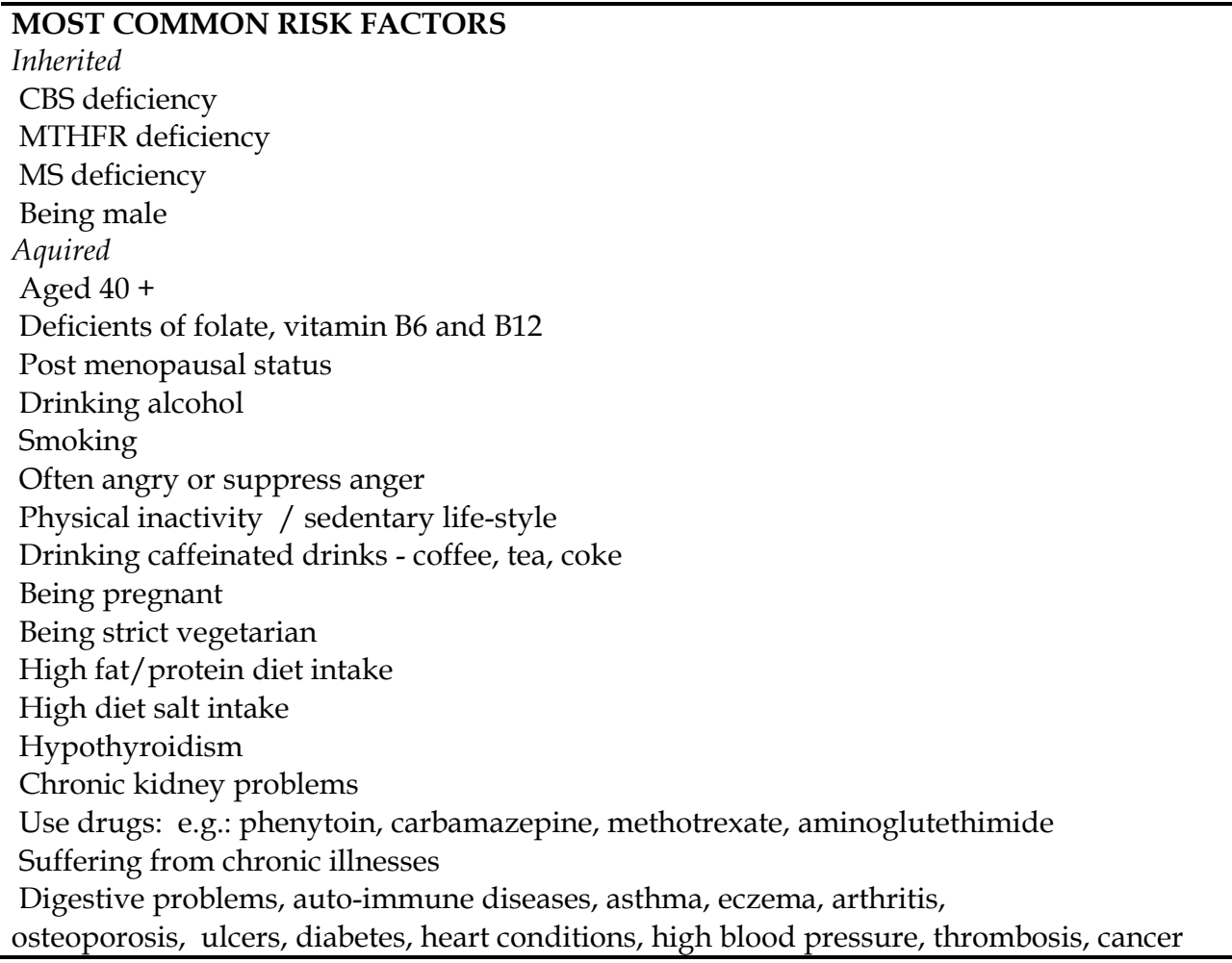

Table 3. Common risk factors inducing mild hyperhomocysteinemia

\section{Venous thromoembolism and hyperhomocysteinemia}

It has been recognized, since the first description of hyperhomocysteinemia, that arterial and venous thrombosis are common in these patients. Patients with homocysteinuria suffered of thrombotic events, cerebrovascular occlusions, deep vein thromboses, myocardial infarctions and peripheral vascular thromboses (Mudd et al., 1985) of which a quarter of all thrombotic events occured before the age of 16 and half before the age of 28 , much earlier in life than would normally be expected for these types of events. Further, patients with CBS deficiency-induced homocysteinuria have high levels of plasma homocysteine (Carey et al., 1968). Interest in the hyperhomocysteinemia condition increased when a large number of studies (mainly retrospective) showed that also mildly elevated homocysteine levels are associated with venous thromboembolism (VTE), thrombotic stroke, and peripheral vascular disease (Wilcken \& Wilcken, 1976, Mudd et al., 1985, Moll, 2004).

To conclude, mild hyperhomocysteinemia can be induced by a variety of risk factors of which the most common genetic factors are heterozygous CBS gene defects and polymorphism in the MTHFR gene at position 677, while as well numerous aquired conditions might be involved (Table 3). 
Independent from other factors hyperhomocysteinemia is associated with a 4.8 fold increased risk for VTE (Köktürk et al., 2010).

\subsection{Mechanisms for thrombosis in hyperhomocysteinemia}

Homocysteine impairs intrinsic thrombolysis and endothelium function (Dalton et al., 1997; Nishio \& Watanabe; 1997). Studies of cultured cells in vitro indicate that homocysteine has prothrombotic effects on the endothelium and vascular smooth muscle. In vitro test results show that endothelial cells are damaged by moderate hyperhomocysteinemia mainly because of the impact of hydrogen peroxide (Hultberg et al., 1997).

Homocysteine though oxidative stress, probably directly damages endothelial cells by: (1) the direct oxidation of low density lipoproteins (2) its cytoplasmic oxidation products like homocystine, mixed disulfides and homocysteine thiolactone, which lead to the development of reactive oxidative species ROS such as hydrogen peroxide, superoxide anion and hydroxide radical (3) acceleration of fibrin and collagen accumulation in endothelial cells and smooth muscle cells, stimulating their proliferation and thus changes the vessel wall leading to or at least accelerating thrombus and vascular disease.

The metabolism of homocysteine is connected with the cellular level of S-adenosyl methionine (SAM) which is a co-substrate involved in methyl group transfers of both the transsulfuration and remethylation metabolic pathways (Fig.2) by the enzyme methyltransferase. At the same time, SAM is the methyl group donor in the methylation of DNA, proteins, phospholipids and biogenic amines. Therefore, the methyltransferase function depends on the cell concentration of both SAM and S-adenosyl homocysteine (SAH). Effectively, high cellular homocysteine levels inhibit vital methylation reactions, affecting the maintenance of the DNA structure; without repair mutations can occur and the structure can collapse. The close connection of homocysteine metabolism with methyl transfer reactions imply, that changed methyl transfer reactions are responsible for some of the effects of altered vessel function during hyperhomocysteinemia.

It is very likely that the mechanisms by which homocysteine changes vessel function are oxidative stress and alterations of cell methylation (Lentz, 1998). The proposed pathogenetic mechanisms which associate hyperhomocysteinemia and vascular injury are oxidative damage of the endothelium through suppression of the vasodilator nitric oxide, increasing the level of asymmetric dimethylarginine, impairing methylation, proliferation of vascular smooth muscle, and disruption of the normal procoagulant balance in favor of thrombosis.

\subsection{Homocysteine and thrombosis in malignancies, renal failure, retina veins}

\subsubsection{Malignancies and VTE}

More recently, increased plasma homocysteine concentration has been postulated as a risk factor for cancer and even as a novel tumor marker (Sun et al., 2002). Patients with malignancies often have an increased risk of VTE disease and as such being the second most common cause of death in cancer patients, second to the primary disease itself (Rickles et al., 1992). In 1865 Trousseau described hypercoagulability and increasing risk of »spontaneous coagulation " in patients with cancer (Trousseau, 1865). Nowadays, it is established that 
breast, pancreas, and gastrointestinal cancers are associated with a higher incidence of thrombosis. With more advanced stages of cancer there is a lower overall survival rate, but, also a greater risk of venous thromboembolism, additionally influencing the survival of patients.

The associated pathophysiology of VTE and malignancies has not been precisely defined. However, it has been reported that cancer patients show increased levels of several procoagulant factors (Falanga et al., 1993). It is well established that women with advanced breast cancer show hyperhomocysteinemia, which explains the hight rate of venous thrombosis in women with metastatic breast malignancy (Smith et al., 2008). Other established contributors to the VTE increased risk are: chemotherapy, hormonal adjuvant therapy, surgery, central venous catheters, immobility and inherited thrombophilia, with the notion that oncological therapies do influence the immunological response.

\subsubsection{Renal failure and VTE}

Under physiological conditions, non-protein bound homocysteine is subjected to glomerular filtration, and almost completely reabsorbed in the tubuli and oxidatively catabolized to carbon dioxide and sulphate in the kidney cells. The clearance is markedly reduced in renal failure with a strong, positive correlation between homocysteine levels, serum creatinine and the glomerular filtration rate (Hultberg et al., 1993). Hyperhomocysteinemia in patients with chronic renal failure induces an oxidative stress to the vascular endothelium, causing a failure in vasodilatation and an impairment of antithrombotic properties. In patients with end-stage renal disease (ESRD) the prevalence of hyperhomocysteinemia is $85-100 \%$ and of the fifty-nine ESRD patients undergoing hemodialysis treatment with supplemented B vitamines it was concluded that the MTHFR C677T mutation is an important genetic determinant of elevated plasma homocysteine concentration level.

\subsubsection{Retinal Vein occlusion}

Several studies have examined the relationship between hyperhomocysteinemia and retinal vein occlusion, a condition affecting approximately five out of 1000 of the general population over 64 years of age (David et al., 1988). The association between retinal vein occlusion, hyperhomocysteinemia and thermolabile MTHFR was confirmed (Janssen et al., 2005).

\subsubsection{Homocysteine and thrombosis in children}

Venous thrombosis in children occurs at a much lower frequency than in adults and the events are usually provoked by acquired risk factors like sepsis, cancer and central venous catheters. The association of VTE and hyperhomocysteinemia in children has been confirmed in two case control studies (Koch et al., 1999; Kosch et al., 2004).

\subsubsection{Hyperhomocysteinemia and pregnancy}

Hyperhomocysteinemia during pregnancy, which is a consequence of perturbations in methionine and/or the folate metabolism, has been implicated in adverse outcomes such as 
neural tube defects, preeclampsia, spontaneous abortion, and premature delivery (Dasarathy et al., 2010). This is pertinent as it is believed that placental thrombosis may contribute to the pathogenesis of these conditions (Gatt \& Makris, 2007).

\section{Treatment of hyperhomocysteinemia}

The treatment of hyperhomocysteinemia varies with the underlying cause.

In the case of deficiency of one or more vitamins involved in homocysteine metabolism, blood levels of this amino acid are often elevated well above those observed in the healthy population. Treatment of hyperhomocysteinemia includes supplementation with mostly pharmacological doses of one or more of the relevant $B$ vitamins and is generally effective in reducing homocysteine concentrations and delays atherosclerotic and thrombotic events.

The negative impact of particular genotypes on homocysteine levels can partly be compensated by folate intake and is, even in smaller part, dependent on several other variables that affect homocysteine levels (see Table 2). For example, if persons have balanced diet with optimal intake of B6 and B12 vitamins and folates it seems that the C677T mutation and the subsequent reduced activity of the enzyme MTHFR do not connect with hyperhomocysteinemia (Schriver et al., 1995; Silaste et al., 2001). Besides, folic acid supplemetation reduces the plasma homocysteine concentration in all three genotypes (TT, CT and CC) of the MTHFR C677T mutation (Meshkin \& Blum, 2007).

This scientific evidence suggests that the MTHFR C677T genetic mutation influences folate metabolism, leading to the conclusion that dietary intake of a standard dosage of folate may be insufficient for half to two-thirds of the population with this mutation (Meshkin \& Blum, 2007).

In the case of CBS deficiency, the enzyme activity can effectively be enhanced by treatment with large doses of vitamin B6.

A combination of all three relevant coenzymes to treat milder forms of hyperhomocysteinemia resulted in a clear 50\% reduction of plasma homocysteine levels. However, given alone, only folic acid was able to induce similar reductions, whereas vitamin B 12 was little effective and vitamin B6 failed to show an effect (Perry et al., 1968, Ubbink et al., 1993; Ubbink et al., 1994).

Many countries have implemented mandatory folic acid fortification of flour and grain products to reduce the risk of various diseases. Besides, individuals can find a good source of folate in fruits and vegetables (especially green leafy vegetables).

\section{Who should be tested for MTHFR mutations and homocysteine levels}

For individuals with unexplained arterial or venous blood clots and unexplained atherosclerosis it seems appropiate having blood homocysteine levels checked. One can also argue that everybody with atherosclerosis, patients with CVD, heart attacks, or strokes, should have their blood checked for homocysteine levels. All this in order to prevent further 
damage. At this time, no clear medical indication exists for women with a history of recurrent pregnancy loss, preeclampsia, placental abruption, and/or small-for-age babies to have homocysteine levels checked, although appropiate clinical research should come with more evidence for this.

As with homocysteine, no official guidelines exist as to who should be tested for MTHFR. In the absence of elevated homocysteine levels, MTHFR mutations appear to have no clinical relevance in regard to thrombosis and atherosclerosis. However, in case of elevated homocysteine levels of MTHFR patients the risk for venous thromoembolism increases dramatically. Since treatment can be relatively easy according to diet, one could argue that there is indication to perform MTHFR genetic testing after the homocysteine test shows elevated levels (Varga et al., 2005).

\section{Conclusion}

Elevated homocysteine concentration has been identified as an independent risk factor for premature cardiovascular disease.

Results of multiple prospective and case control studies have shown that patients with a moderately elevated plasma homocysteine concentration are more likely to develop venous and arterial thrombosis compared to the control population. Homocysteine seems to promote atherothrombosis by a variety of mechanisms. The precise pathogenic mechanism remains to be confirmed and it is not yet clear whether homocysteine itself or a related metabolite or a cofactor is primarily responsible for the atherothrombogenic effects of hyperhomocysteinemia. However, recent studies indicate that lowering an elevated homocysteine level does decrease the risk of atherosclerosis and blood clots. Until this issue has been more clearly defined, it appears prudent to make an effort to try to lower one's homocysteine levels through supplementation with B vitamins, which is an efficient and safe way to reduce an elevated homocysteine levels.

The MTHFR mutations appear to be medically irrelevant, as long as an individual's homocysteine level is normal. Therefore, it should be first the homocysteine level, not the MTHFR genetic status, to be tested in patients with or at risk for blood clots, atherosclerosis, or pregnancy complications.

It is well estabilished that healthly lifestyle lowers homocysteine concentrations. So the most important in everyday life is awareness that the level of homocysteine in blood is strongly influenced by several lifestyle factors such as nutrition, stress, smoking cigarettes, alcohol consumption, or physical inactivity. And therefore, exercise is a commonly recommended lifestyle intervention for individuals at risk for, or diagnosed with, cardio vascular disease. More specifically, we suggest that exercise, mild in aged people, but especially heavy physical activity, exerts its most favorable effect in subjects with hyperhomocysteinemia.

\section{Acknowledgement}

The authors wish to thank Dr. Cécil J.W. Meulenberg for proofreading and useful suggestions. 


\section{References}

Barak AJ, Beckenhauer HC, Hidiroglou N, Camilo ME, Selhub J \&Tuma DJ. (1993). The relationship of ethanol feeding to the methyl folate trap. The Journal of alcoholism, Vol.10, No.6, (1993), pp. 495-497, ISSN: 0021-8685.

Butz LWV \& du Vigneaud V. (1932). The formation of a homologue of cystine by the decompensation of methionine with sulfuric acid. Journal of Biological Chemistry, Vol.99, pp. 135-142, ISSN 0021-9258.

Bolander-Gouaille C. (2001). Focus on Homocysteine, Springer-Verlag France, ISBN 2287596828, Berlin (etc).

Blount BC, Mack MM, Wehr CM, Mac Gregor JT, Hiatt RA Wang G, Wickramasinghe SN , Everson RB \& Ames BN. (1997). Folate deficiency causes uracil misincorporation into human DNA and chromosome breakage: Implications for cancer and neuronal damage. Proceedings of the National Academy of Sciences of the United States of America, Vol.94, No.7, (1997), pp. 3290-3295, ISSN: 1091-6490.

Carey MC, Fennelly JJ \& Fitz Gerald 0. (1968). Homocystinuria II. Subnormal serum folate levels, increased folate clearance and effects of folic acid therapy. American Journal of Medicine, Vol.45, (1997), pp. 26, ISSN: 0002- 9343.

Carson N \& Neill DW. (1962). Metabolic abnormalities detected in a survey of mentally backward individuals in Northern Ireland. Archives of Disease in Childhood, Vol.37, (1962) pp. 505-513, ISSN: 00039888.

Cattaneo M. Hyperhomocysteinemia and Venous Thromboembolism. (2006). Seminar in Thromobosis and Hemostasis, Vol.32, No.7, (2006), pp. 716-723, ISSN: 0094-6176.

Dalton ML, Gadson PFJr, Wrenn RW \& Rosenquist TH. (1997). Homocysteine signal cascade: production of phospholipids, activation of protein kinase C, and the induction of c-fos and c-myb in ssmooth muscle cells. Federation of American Societies for Experimental Biology, Vol.11, (1997), pp. 703-711, ISSN:0892-6638.

David R, Zamgwill L, Badarna M \& Yassur Y. (1988). Epidemiology of retinal vein occluson and its association with glaucoma and increased intraocular pressure. Ophthalmologica, Vol. 197, (1988), pp. 69-74, ISSN: 0030-3755.

Dasarathy J, Gruca LL, Bennett C, Parimi PS, Duenas C, Marczewski S, Fierro JL \& Kalhan SC. (1998). Methionine metabolism in human pregnancy. Current Opininion of Hematology, Vol.5, No.5, (1988), pp. 343-349, ISSN: 1065-6251.

De Bree A, Van Dusseldorp M, Brouwer IA, Van het Hof KH \& Steegers- Theunissen RPM. (1997). Folate intake in Europe: recommended, actual and desired intake. European Journal of Clinical Nutrition; Vol.51, (1997), pp. 643-660, ISSN: 0954-3007.

Dinesh-K, K. (2004). Homocysteine and Cardiovascular Disesase. Current Atherosclerosis Reports, Vol.6, (2004), pp.101-106, ISSN: 1523-3804.

Falanga A, Ofosu FA, Cortelazzo S, Delaini F, Consonni R, Caccia R, Longatti S, Maran D, Rodeghiero F, Pogliani E, et al.(1993). Preliminary study to identify cancer patients at high risk of venous thrombosis following major surgery. British Journal of Haematology, Vol.85, No.4, (1993), pp. 745-750, ISSN: 0007-1048.

Fodinger M, Horl WH \& Sunder-Plassmann G. (2000). Molecular biology of 5,10methylenetetrahydrofolate reductase. Journal of Nephrology, Vol.13, (2000), pp. 2033, ISSN: 1121-8428. 
Gatt A \& Markis M. Hyperhomocysteinemia and Venous Thrombosis. (2007). Seminars in Hematology, Vol. 44, (2007), pp. 70-76, ISSN: 00371963.

Gatt A, Makris A, Cladd H, Burcombe RJ, Smith JM, Cooper P, Thompson D \& Makris M. (2007). Hyperhomocysteinemia in women with advanced breast cancer. International Journal of Laboratory Hematology, Vol.29, No.6, (2008), pp.421-425, ISSN:1751 -5521.

Godin CS \& Crooks PA. (1986). In vitro inhibition of histamine metabolism in guinea pig lung by S-(-)-nicotine. Journal of Pharmaceutical Sciences, Vol.75, No.10, (1986), pp.945-95, ISSN: 0022-3549.

Graham IM, Daly LE, Refsum HM, Robinson K, Brattström LE, Ueland PM, Palma-Reis RJ, Boers GH, Sheahan RG, Israelsson B, Uiterwaal CS, Meleady R, McMaster D, Verhoef P, Witteman J, Rubba P, Bellet H, Wautrecht JC, de Valk HW, Sales Lúis AC, Parrot-Rouland FM, Tan KS, Higgins I, Garcon D, Andria G, et al. (1997). The European Concerted Action Project. Journal of the American Medical Association, Vol. 227, (1997), pp.1775-1781, ISSN: 00987484.

Hankey GJ \& Eikelboom JW. (1999). Homocysteine and vascular disease. Lancet, Vol.354, No.9176, (1999), pp. 407-413, ISSN: 0140-6736.

Hultberg B, Andersson A \& Sterner G. (1993). Plasma homocysteine in renal failure. Clinical Nephrology, Vol.40, (1993), pp. 223-235, ISSN: 0301- 0430.

Hultberg B, Andersson A \& Isaksson A. (1997). The effects of homocysteine and copper ions on the concentration and redox status of thiols in cell line cultures. Clinica Chimica Acta, Vol.262, No.1-2,(1997), pp.39-51, ISSN: 0009-8981.

Janssen MC, den Heijer M, Cruysberg JR, Wollersheim H \& Bredie SJ. (2005). Retinal vein occlusion: A form of venous thrombosis or a complication of atherosclerosis? A meta- analysis of thromophilic factor. Journal of Thrombosis and Haemostasis, Vol.93, (2005), pp. 1021-1026, ISSN: 1538-7933.

Koch HG, Nabel P, Junker R, Auberger K, Schobess R \& Homberger A. (1999). The 677T genotype of the common MTHFR thermolabile variant and fasting homocysteine in childhood venous thrombosis. European Journal of Pediatrics, Vol.158, (1999), pp.113116, ISSN: 0340- 6199.

Köktürk N, Kanbay A, Aydogdu M, Ozyilmaz E, Bukan N \& Ekim N. (2010). Hyperhomocysteinemia Prevalence Among Patients with Venous Thromboembolism. Clinical and applied thrombosis/hemostasis, (August 2010), doi: 10.1177/1076029610378499. ISSN: 1076-0296

Kosch A, Koch HG, Heinecke A, Kurnik k, Heller C \& Nowak-Gottl U. (2004). Increased fasting total homocysteine plasma levels as a risk factor for thromboembolism in children. Journal of Thrombosis and Haemostasis, Vol.91, (2004), pp. 308-314, ISSN: 1538-7933.

Lentz SR. (1998). Mechanisms of thrombosis in hyperhomocysteinemia. Current Opinion in Hematology, Vol.5, No.5 (1998), pp.309-359, ISSN: 1065-6251

MCCully KS. (1969). Vascular pathology of homocysteinemia: implications for pathogenesis of arteriosclerosis. American Journal of Pathology, Vol.56, (1969), pp. 111-128, ISSN: 00029440. 
Meshkin B \& Blum K. (2007). Folate Nutrigenetics: A Convergence of Dietary Folate Metabolism, Folic Acid Supplementation, and Folate Antagonist Pharmacogenetics. Drug Metabolism Letters, Vol.1, (2007), pp. 55-60, ISSN: 18723128.

Miller DR, Specker BL, Ho ML \& Norman EJ. (1991). Vitamin B12 status in macrobiotic community. American Journal of Clinical Nutrition, Vol.53, (1991), pp.524-529. ISSN: 1938-3207.

Moat SJ, Lang D, McDowell IF, Clarke ZL, Madhavan AK, Lewis MJ \& Goodfellow J. (2004). Folate, Homocysteine, Endothelial function and Cardiovascular disease. Journal Nutritional Biochemistry, Vol.15, No.2, (2004), pp. 64-79, ISSN: 09552863.

Moll S. (2004). Homocysteine, 10.07.2011, Availbale from: <Http://www.fvleiden.org/ask/77.html>.

Mudd SH, Edwards WA, Loeb PM, Brown MS \& Laster L. (1970). Homocystinuria due to cystathionine synthase deficiency: the effect of pyridoxine. Journal of Clinical Investigation, Vol.49, (1970), pp. 1762, ISSN: 00219738.

Mudd SH, Skovby F, Levy HL, Pettigrew KD, Wilcken B, Pyeritz RE, Andria G, Boers GHJ, Bromberg IL, Cerone R, Fowler B, Grobe H, Schmidt H \& Schweitzer L. (1985). The natural hystory of homocystinuria due to cystathionine beta-synthase deficiency. The American Journal of Human Genetics, Vol.37, No.1, (1985), pp.1-33, ISSN: 00029297.

Nishio E \& Watanabe Y. (1997). Homocysteine as a modulator of plateled- derived growth factor action in vascular smooth muscle cells: a possible role for hydrogen peroxide. British Journal of Pharmacology, Vol.122, (1997), pp. 269-274, ISSN: 1476-5381.

Nygård O, Vollset SE, Refsum H, Stensvold I, Tverdal A, Nordrehaug JE, Ueland M \& Kvåle G. (1995). Total plasma homocysteine and cardiovascular risk profile. The Hordaland Homocysteine Study, Journal of the American Medical Association, Vol. 274, No.19, (1995), pp. 1526-1533, ISSN: 00987484.

Nygård O, Nordrehaug JE, Refsum H, Ueland PM, Farstad M \& Vollset SE. (1997a). Plasma homocysteine levels and mortality in patients with coronary artery disease. The New England Journal of Medicine, Vol. 337, No.4, (1997), pp. 230-236, ISSN: (1997a), ISSN:1533-4406.

Nygård O, Refsum H, Ueland PM, Stensvold I, Nordrehaug JE, Kvåle G \& Vollset SE. (1997b). Coffee consumption and plasma total homocysteine: The Hordaland Homocysteine Study. The American Journal of Clinical Nutrition, Vol.65. No. 1, (1997), pp.136-143, ISSN: 0002-9165.

Pennypacker LC, Allen RH, Kelly JP, Matthews LM, Grigsby J, Kaye K, Lindenbaum J \& Stabler SP.(1992). High prevalence of cobalamin deficiency in elderly outpatients. The Journal of the American Geriatrics Society, Vol. 40, No. 12, (1992), pp. 1197-1204, ISSN: 0002-8614.

Pettersson T, Friman C, Abrahamsson L, Nilsson B \& Norberg B. (1998). Serum homocysteine and methylmalonic acid in patients with rheumatoid arthritis and cobalaminopenia. Journal of Rheumatology, Vol.25, (1998), pp. 859-863, ISSN: 14992752.

Perry TL, Hansen S, Love LD, Crawford LE \& Tischler B. (1968). Tretament of homocystinuria with a low- methionine diet, supplemental cysteine and a methyl donor. Lancet, Vol.292, No.7566, (1968), pp. 474 - 478. ISSN: 0140-6736. 
Pietrzik P\& Brönstrup A. (1998). Vitamins B12, B6 and folate as determinants of homocysteine concentration in the healthy population. European Journal of Pediatrics, Vol.157, No.2, (1998), pp. S135-S138. ISSN: 1432-1076.

Plazar N. Jurdana M \& Pišot R. (2008). The effect of 35-day bed rest on plasma homocysteine concentration. Farmacevtski vestnik, Vol.59, No.6, (2008), pp. 319-322, ISSN: 00148229.

Rickles FR, Levine M \& Edwards RL. (1992). Hemostatic alteration in cancer patients. Cancer and Metastasis Review, Vol.11, (1992), pp. 237-248, ISSN: 1573-7233.

Ridker PM, Manson JE, Buring JE, Shih J, Matias M \& Hennekens CH. (1999). Homocysteine and risk of cardiovascular disease among postmenopausal women. Journal of the American Medical Association, Vol.281, (1999), pp. 1817-1821, ISSN: 0098748.

Schriver RC, Beaudet AL, Sly WS \& Valle D. (1995). The metabolic and molecular basis of inherited disease, Mc-Graw-Hill, ISBN 0-07-105432-4 New York. P. 1276-1319.

Silaste ML, Rantala M, Sämpi M, Alfthan G, Ato A \& Kasänieiemi A. (2001). Polimorphisms of key enzymes in homocysteine metabolism affect diet responsiveness of plasma homocysteine in healthy women. Journal of Nutrition; Vol.131, (2001), pp. 2643-2647, ISSN: 0022-3166.

Stanger O, Herrmann W, Pietrzik K, Flower B, Geisel J, Dierkes J \& Weger M. (2003). DACHLIGA Homocystein (German, Austrian and Swiss Homocysteine Society): Consensus paper on the regional clinical use of homocysteine, folic acid and Bvitamins in cardiovascular and thrombotic diseases: guidelines and recommendations. Clinical Chemistry and Laboratory Medicine, Vol.41, (2003), pp. 1392-13403, ISSN: 1434-6621.

Sun CF, Haven TR, Wu TL, Tsao KC \& Wu JT. (2002). Serum total homocysteine increases with the rapid proliferation rate of tumor cells and decline upon cell death: a potential new tumor marker. Clinica Chimica Acta, Vol. 321, (2002), pp: 55-62., ISSN: 0009-8981.

Trosseau A. (1865). Phlegmasia alba dolens. Clinique médicale de l'Hôtel-Dieu de Paris, Vol.3, (1865), pp.654-712. ISBN-10: 0543873021.

Ulvike A, Vollset SE, Hoff G \& Ueland PM. (2008). Coffee consumption and circulating Bvitamins in healthy middle-aged men and women. Clinical Chemistry, Vol.54, No.9, (2008), pp.1489-1496, ISSN: 0009-9147.

Ubbink JB, van dr Merwe A, Vermaak WJH \& Delport R. (1993). Hyperhomocysteinemia and the response to vitamin supplementation. Journal of Clinical Investigation, Vol.71, (1993), pp. 993-998, ISSN: 0021-9738.

Ubbnik JB, Vermaak WHJ, van der Merwe A, Becker PJ, Delport R \& Potgieter HC. (1994). Vitamin requierments for the treatment of hyperhomocysteinemia in humans. Journal of Nutrition, Vol.124, pp. 1927-1933, ISSN: 0022-3166.

Varga EA, Sturm AC, Misita CP \& Moll S. (2005). Homocysteine and MTHFR Mutations: relation to Thrombosis and Coronary Artery Disease. Circulation, Vol.111, (2005), pp. 289-293, ISSN: 0009-7322.

Watanabe F, Abe K, Fujita T, Goto M, Hiemori M \& Nakano Y. (1998). Effects of microwave heating on the loss of vitamin B12 in foods. Journal Agricolture Food Chemistry, Vol.46, No.1, (1998), pp. 206-210, ISSN: 0021-8561. 
Weisberg IS, Park E, Ballman KV, Berger P, Nunn M, Suh DS, et al. (2003). Investigations of a common genetic variant in betaine-homocystein methyltransferase (BHMT) in coronary artery disease. Atherosclerosis, Vol.167, (2003), pp. 205-214, ISSN: 00219150.

Wilcken DE \& Wilcken B. (1967). The pathogenesis of coronary artery disease. A possible role for methionine metabolism. Journal of Clinical Investigation, Vol.57, (1967), pp. 1079-1082, ISSN: 0021-9150. 
PATHOQMYSIOIOGY ANO CUNICAL ASPECTS OO

VENOUS

THROMBOEMBOLISM IN

NEONATES, RENAL DISEASE

AND CANCER PATIENTS

Ested by Motumes A. Abdelasl

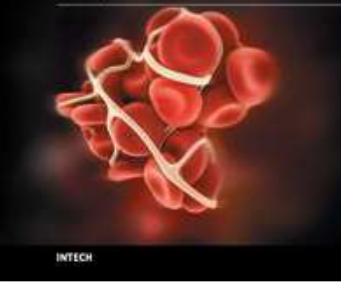

Pathophysiology and Clinical Aspects of Venous

Thromboembolism in Neonates, Renal Disease and Cancer

\section{Patients}

Edited by Dr. Mohamed A. Abdelaal

ISBN 978-953-51-0616-6

Hard cover, 166 pages

Publisher InTech

Published online 16, May, 2012

Published in print edition May, 2012

Venous Thromboembolism remains a major health challenge in many countries because of the morbidity and mortality it inflicts, mainly in hospitalized patients. This book, with contributions from distinguished experts in the field, depicts some hot aspects on aetilogics of VTE, the disease burden in neonates, renal disease and cancer patients as well as issues relevant to prophylaxis and the concept of VTE as patient injury content.

\section{How to reference}

In order to correctly reference this scholarly work, feel free to copy and paste the following:

Nadja Plazar and Mihaela Jurdana (2012). Hyperhomocysteinemia: Relation to Cardiovascular Disease and Venous Thromboembolism, Pathophysiology and Clinical Aspects of Venous Thromboembolism in Neonates, Renal Disease and Cancer Patients, Dr. Mohamed A. Abdelaal (Ed.), ISBN: 978-953-51-0616-6, InTech, Available from: http://www.intechopen.com/books/pathophysiology-and-clinical-aspects-of-venousthromboembolism-in-neonates-renal-disease-and-cancer-patients/hyperhomocysteinemia-relation-tocardiovascular-disease-and-venous-thromboembolism

\section{INTECH}

open science | open minds

\section{InTech Europe}

University Campus STeP Ri

Slavka Krautzeka 83/A

51000 Rijeka, Croatia

Phone: +385 (51) 770447

Fax: +385 (51) 686166

www.intechopen.com

\section{InTech China}

Unit 405, Office Block, Hotel Equatorial Shanghai

No.65, Yan An Road (West), Shanghai, 200040, China

中国上海市延安西路65号上海国际贵都大饭店办公楼405单元

Phone: +86-21-62489820

Fax: $+86-21-62489821$ 
(C) 2012 The Author(s). Licensee IntechOpen. This is an open access article distributed under the terms of the Creative Commons Attribution 3.0 License, which permits unrestricted use, distribution, and reproduction in any medium, provided the original work is properly cited. 